\title{
Shoreline behind a breakwater for wave energy absorption in Reggio Calabria: comparison between theoretical models and experimental data
}

\author{
G. Barbaro \& G. Foti \\ Department of Mechanics and Materials, \\ Reggio Calabria "Mediterranea" University, Italy
}

\begin{abstract}
This paper deals with models proposed for calculating the shoreline change behind a breakwater. In particular, models developed by Hsu and Silvester, McCormick, Gonzalez and Medina and Hsu et al. are discussed. Shoreline change behind a breakwater is estimated by these models. Results are compared with experimental data measured at the NOEL laboratory of Reggio Calabria, for a caisson breakwater for wave energy absorption made using nine cellular caissons in reinforced concrete. The structure is $16.2 \mathrm{~m}$ long and located in a $2 \mathrm{~m}$ water depth. Waves in the undisturbed wave field are measured at the same water depth, $20 \mathrm{~m}$ away from the structure, by means of two pressure transducers and two ultrasonic probes located on two piles of small diameter $(0.05 \mathrm{~m})$. Tide is measured by probes in the undisturbed wave field and by pressure transducers on the breakwater.

Keywords: shoreline, breakwater, modelling, salient, tombolo.
\end{abstract}

\section{Introduction}

Caisson breakwaters are widely used for shoreline protection. Their target is to induce accretion of the shore, in order to protect it from erosion processes, and, further, to increase the attraction of the location. With this purpose, they create a safe basin and, at the same time, they modify the cross-shore circulation.

There has been an increasing use of caisson breakwaters for coastal protection during the last two decades. 
Usually, they are placed in front of, and parallel to, a shoreline. They dissipate sea wave energy and induce a sediment deposit in the safe area. The hydrodynamic and the sediment transport mechanics, close to the breakwater, are not completely known. Based on experimental investigations, some models have been proposed. They focus on the estimation of the shoreline change by considering the occurrence of a salient or a tombolo. There is a tombolo, when the accretion is such that the shoreline reaches the breakwater. Otherwise, there is a salient. Most part of the afore-mentioned models estimate shoreline change by assuming an orthogonal wave train interacting with one barrier (Shinohara and Tsubaki [5]; Rosen and Vajda [6]; Mimura et al. [7]; Ming and Chiew [8]).

Various parameters have been considered for determining shoreline change. For example, the length $B$ of the breakwater, the shoreline-breakwater distance $S$, the breaking depth $d_{b}$, the wave steepness $H_{0} / L_{0}$, the mean sediment diameter $D_{50}$, the sediment density $\rho_{s}$, beach slope $S_{b}$.

Some authors (Gourlay [9]; SPM [10]; Dally and Pope [11]; Suh and Dalrymple [12]; Ahrens and Cox [13]) have proposed empirical formulations for estimating the shoreline change behind a breakwater. However, there are different criteria for defining the occurrence of a tombolo or a salient.

\section{Previous works about the analysis of a tombolo or a salient behind a breakwater}

The following models for the analysis of shoreline change due to a breakwater are reviewed: Hsu and Silvester [1], McCormick [2], Gonzalez and Medina [4], Hsu et al. [3].

\subsection{Hsu and Silvester}

Hsu and Silvester [1] model gives the shoreline change by considering a polar coordinate system with origin at the tip of the breakwater. The shoreline is symmetric with respect to the centre of the breakwater. It is estimated by the equation

$$
r(\theta)=f(\theta) r\left(40^{\circ}\right)
$$

$\theta$ being the angular variable. In eq. (1), $40^{\circ}<\theta<180^{\circ}, f(\theta)$ is a decreasing function of $\theta$. Then, $r\left(40^{\circ}\right)$ is defined by the equations

$$
r\left(40^{\circ}\right)=0.17 B+1.68 S
$$

The intersection between the shoreline and a line orthogonal to the breakwater that contains the centre of the breakwater is a cusp.

The authors suggested to correct the shoreline equation, by considering the distance $X$ between the centre of the breakwater and the shoreline:

$$
X=0.6784 B(B / S)^{-1.2148}
$$




\subsection{McCormick elliptic model}

Assume a coordinate system with origin at the centre of the breakwater (Fig. 1). Then, assume one breakwater under the action of an orthogonal wave train. McCormick [2] proposed the elliptic equilibrium shoreline, given by the equation

$$
\frac{(y \mp h)^{2}}{a^{2}}+\frac{x^{2}}{b^{2}}=1
$$

where the $x$-axis is orthogonal to the shoreline and landward-oriented and the $y$ axis is parallel to the shoreline, $h$ is the distance between the centre of the breakwater and the centre of the ellipse, $a$ is the semi major axis and $b$ the semi minor axis, $S$ the distance between the breakwater and the original shoreline. The positive and negative sign are referred to, respectively, the right and left side of the shoreline. Foci are at the tips of the barrier.

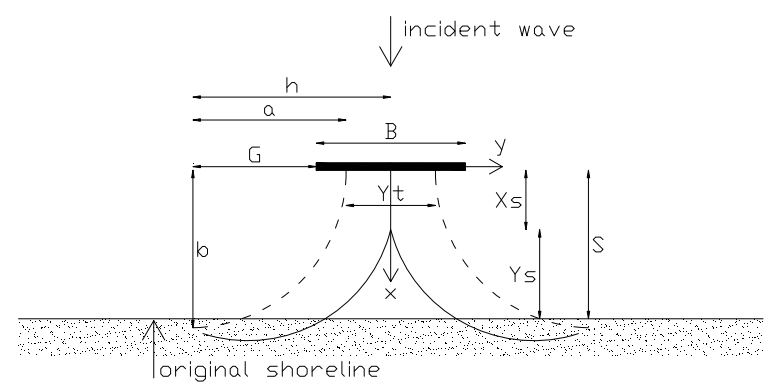

Figure 1: Reference sketch of the elliptic shoreline model (McCormick [2]). The continuous line is a salient, the dashed line is a tombolo.

In eq. (4) $h, a$ and $b$ depend on the wave steepness $H_{0} / L_{0}$ of the incident wave, the beach slope $S_{b}$, the breakwater width $B$, the distance $S$. McCormick [2] suggested the following equations for estimating the ratio $b / S$ :

$$
\frac{b}{S}=1+0.2 \varsigma_{0} \sin \left(\chi \varsigma_{0}\right)
$$

in which $\varsigma_{0}$ is the ratio between the wave steepness and the beach slope:

$$
\varsigma_{0}=\frac{\left(H_{0} / L_{0}\right)}{S_{b}}
$$

and $\chi$ is a parameter that depends on the ratio between beach slope and the breakwater width. It is given by 


$$
\chi=-1.92\left(\frac{S}{B}\right)^{2}+9.92\left(\frac{S}{B}\right)
$$

Further, the distance $h$ is given by the equation

$$
h=G+0.5 B
$$

where $G$ is the distance between the centre of the ellipse and the tip of the breakwater. The semi major axis $a$ is given by

$$
a=\sqrt{G^{2}+b^{2}}
$$

The ratio $G / b$ depends on $\varsigma_{0}$ and on $S / B$. It is given by

$$
\frac{G}{b}=\exp \left[\ln (\mu)+\sigma \ln \left(\varsigma_{0}\right)-v \varsigma_{0}\right]
$$

In eq. (10) $\mu, \sigma, v$ have been defined as

$$
\begin{gathered}
\ln (\mu)=19.4 \tanh \left(0.91 \frac{S}{B}\right) \\
\sigma=17 \tanh \left(0.59 \frac{S}{B}\right) \\
v=20 \tanh \left(0.99 \frac{S}{B}\right)
\end{gathered}
$$

McCormick has derived the distance $X_{s}$ between the salient and the breakwater:

$$
X_{s}=b \sqrt{1-\left(\frac{h}{a}\right)^{2}}
$$

where $a$ is greater than $h$. Otherwise, there is a tombolo and $X_{s}=0$.

\subsubsection{Hsu and Jan and Wen modified elliptic shoreline}

Hsu et al. [3] modified McCormick model [2] by means of the experimental data of Ming and Chiew [8], Shinohara and Tsubaki [5], Rosen and Vajda [6]. In particular, they proposed the following equations for the estimation of $b / S$, given $\varsigma_{0}, S / B$ and $D_{50}$. That is,

$$
\frac{b}{S}= \begin{cases}1+0.2\left(\varsigma_{0}\right)^{1 / 2}\left(\frac{S}{B}\right)^{-5 / 4} & \text { per } D_{50}=0.25 \mathrm{~mm} \\ 0.9+0.2 \varsigma_{0} & \text { per } D_{50}=0.64 \mathrm{~mm}\end{cases}
$$


Further, they proposed the following expression of $G / b$, given $\mu, \sigma$ and $v$ :

$$
\frac{G}{b}=\frac{5}{8} \exp \left[\ln (\mu)+\sigma \ln \left(\varsigma_{0}\right)-v \varsigma_{0}\right]
$$

\subsection{Gonzalez and Medina}

Gonzalez and Medina [4] have investigated shoreline change behind a breakwater by considering, separately, a tombolo and a salient.

Consider the distance between the breakwater and the shoreline, and the breakwater width. If they are smaller than the incident wave length, behind the breakwater there is accretion. The shoreline reaches the breakwater (Figure 2). In this context, the profile depends on the length $2 B$ of the breakwater and on the distance $Y$ between the breakwater and the shoreline, and the wave length $L$, which defines $\alpha_{\min }$ in eq. (17). The shoreline length affected by the breakwater $2 B_{1}$, and the attachment width at the breakwater, $B_{k}$, can be obtained from Hsu and Evans [15] model and eq. (17).

$$
\begin{gathered}
\alpha_{\min }=\arctan \left[\frac{\left(\frac{\beta_{r}^{4}}{16}+\frac{\beta_{r}^{2}}{2} \frac{Y}{L}\right)^{1 / 2}}{\frac{Y}{L}}\right] \\
\beta_{r}=2.13
\end{gathered}
$$

If the breakwater is far from the shoreline and its length is short with respect to the incident wave length, there will be a salient. In this context, the variables used in the context of a tombolo are considered. The salient apex $Y_{0}$ (Figure 3 ) is estimated by the parabolic-shaped formulation of Hsu and Evans [15] and eq. (17).

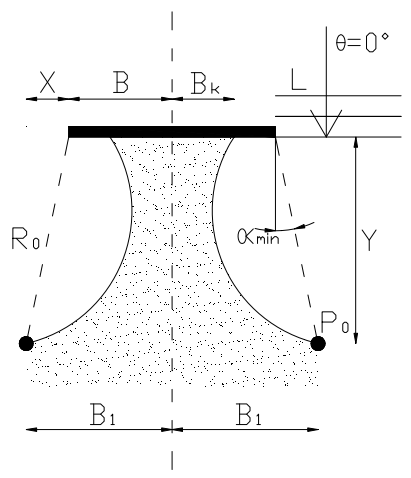

Figure 2: Gonzalez and Medina [4] model for the estimation of a tombolo behind a breakwater. 


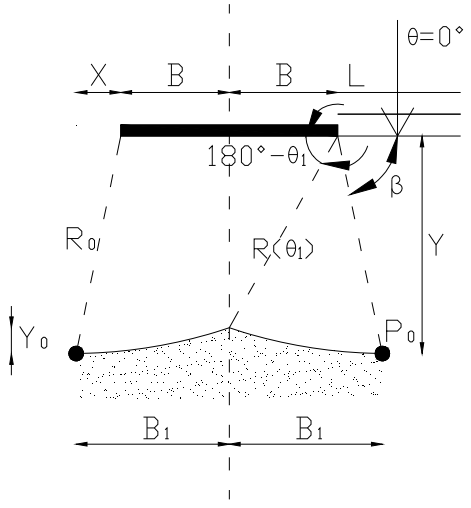

Figure 3: Gonzalez and Medina [4] model for the estimation of a salient behind a breakwater.

Figure 4 shows the graph given by Gonzalez and Medina [4] for calculating shoreline change, that is the lengths $2 B_{l}$ and $B_{k}$ (for a tombolo), and the length $2 B_{I}$ and apex $Y_{0}$ (for a salient).

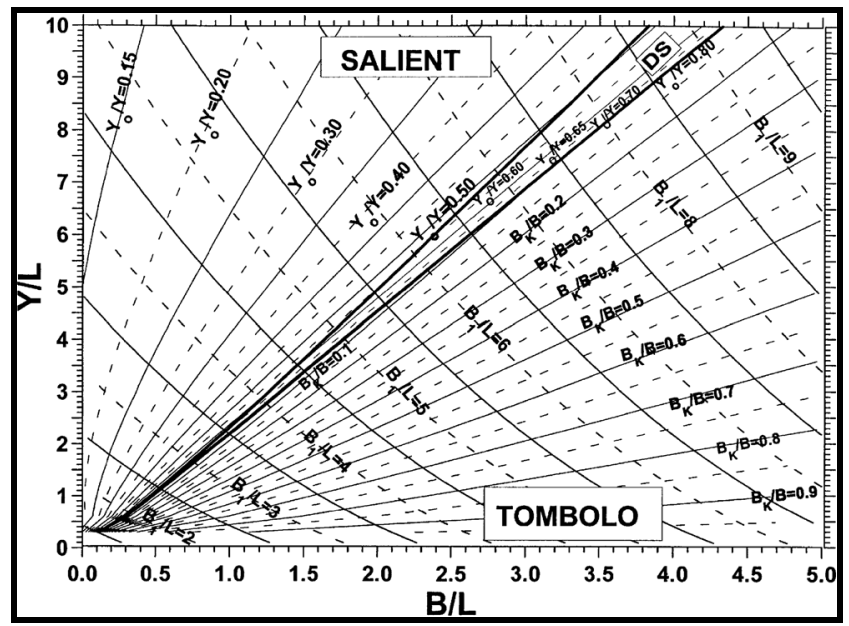

Figure 4: Determination of a tombolo $\left(B_{k} / B, B_{l} / L\right)$ or a salient $\left(Y_{0} / Y, B_{l} / L\right)$ given the nondimensional length of the breakwater and the nondimensional distance between the breakwater and the shoreline.

\section{Experiment RC 2005}

In Reggio Calabria the wind frequently produces waves with dimensions typical of big channels laboratory, which are very stable in time. Waves represent excellent small scale models in the Froude similarity of strong sea storms. We 
refer to the 1:30 small scale models of strong Mediterranean sea storms or the 1:50 scale models of oceanic storms. This peculiarity depends on a favourable combination of hardly repeatable environmental conditions; first, the high stability of the local wind, the so-called "wind of the Strait", blowing from Messina toward Reggio for many consecutive days; second, the orientation of the coast (see fig. 5), which is naturally protected from the swells that propagate from the Southern mouth of the Strait (which are not small scale Froude models of wind waves, of course); finally, the excursion of tide is very contained, and the water is clean thanks to the passage twice a day of the Strait current. The clearness of the water is another requisite for the experimental activity in the sea. In fact, in the sea, all the assemblages are performed by scuba divers.

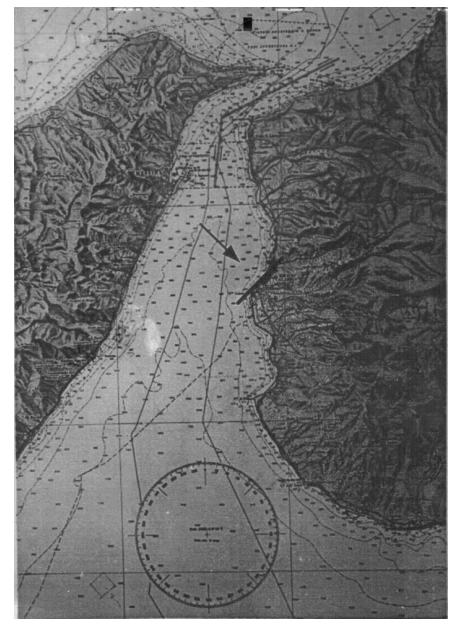

Figure 5: $\quad$ Site of laboratory.

\subsection{Description of the experiment RC 2005}

On March 2005 the small-scale model of a breakwater embodying an OWC has been built in the NOEL (Natural Ocean Engineering Laboratory) laboratory of Reggio Calabria. The breakwater length is $16.2 \mathrm{~m}$. The water depth is $2 \mathrm{~m}$, with seabed slope of $5 \%$. The distance between the centre of the breakwater and the shoreline is $14.7 \mathrm{~m}$. The mean diameter of the sediment is $D_{50}=6 \mathrm{~mm}$. The plant is the 1:10 scale model (with some modifications) of a hypothesis of breakwater for the North-East Pacific coast. Alternatively, this plant may be thought of as the 1:6 scale model of a breakwater suited for the Mediterranean Sea. The aim of the experiment was to test the plant absorption capability. In the undisturbed wave field, at the same water depth, $20 \mathrm{~m}$ far from the structure, 2 piles of small diameter $(0.05 \mathrm{~m})$ with two pressure transducers and two ultrasonic wave probes were placed for supporting the gauges for the measurement of the mean energy flux of the incident waves. Tide is measured by probes in the undisturbed wave 


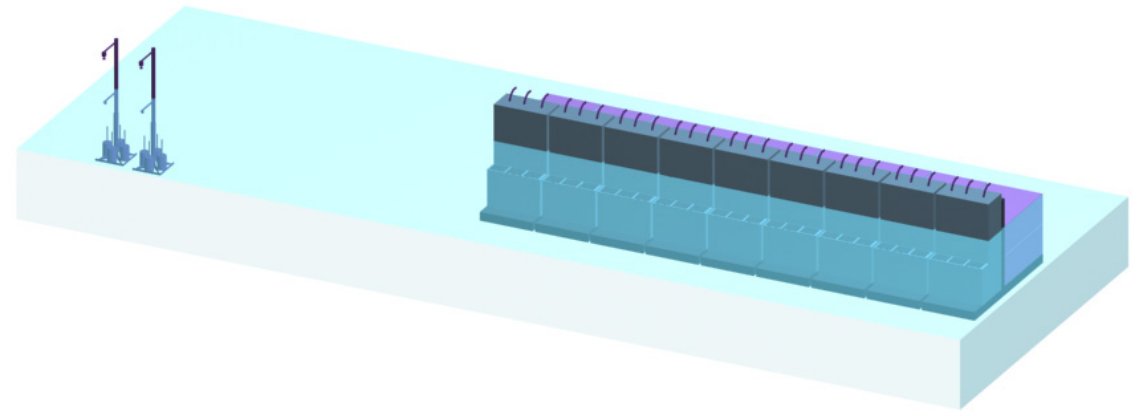

Figure 6: Three-dimensional view of the breakwater used during the RC 2005 experiment and the position of the instruments (Boccotti et al. [16]).

field and pressure transducers on the breakwater. Results of the experiment (Boccotti et al. [16]) showed that it is possible to absorb a large share of the wave energy. Further, it has been measured the shoreline profile behind the breakwater. It has been measured a significant modification of the shoreline.

\subsection{Data stored}

The duration of each record was of five minutes. The sampling rate was of 10/s for each gauge. In each record we obtained the values of the following variables: $H_{s}, T_{p}, \Psi^{*}$ of the incident waves, with $\Psi^{*}$ being the narrow-bandedness parameter (Boccotti [17]), the tide level, the average angle of the wave direction, the absorption coefficient, the amplification factor, the significant height of the oscillations of the water column, the significant height of the fluctuating pressure head in the air pocket and the resonance coefficient. Besides these parameters we obtained the frequency spectrum of the time series data for each gauge, the directional spectrum and the regression.

We got 187 records: 96 records of wind waves, 31 records of wind waves superimposed on swells, a sequence of 40 records of swells of average $T_{p}$ about 5 $\mathrm{s}$ and a sequence of 20 records of swells of average $T_{p}$ about $7 \mathrm{~s}$. The mean significant wave height has been $0.26 \mathrm{~m}$, the peak period has been $4.41 \mathrm{~s}$ (Boccotti et al. [16]), the offshore mean dominant wave length has been $30.35 \mathrm{~m}$ while the mean dominant wave length at the breakwater depth has been $18.2 \mathrm{~m}$.

\section{Comparison between theoretical models and experimental data}

\subsection{Shoreline measured in Reggio Calabria}

The shoreline has been measured three months after the breakwater placing (June 2005), and in September 2010.

Figure 7 shows that the shoreline is not symmetric with respect to the centre of the breakwater. Indeed, the salient apex has moved to the south direction and 
the erosion has involved, in particular, the North side of the shoreline. This asymmetry is, probably, due to the non-parallel position of the breakwater (with respect to the shoreline) and to the occurrence of oblique wave trains.

Further, Figure 7 shows that there have been significant modifications from 2005 to 2010. In particular: the salient apex is closer to the breakwater and there is still the erosion of the external sides. Table 1 shows the shoreline measured variations. Further, it is shown the shoreline asymmetry. Table 1 shows that, in the 2005-2010 time interval, the asymmetry has increased.

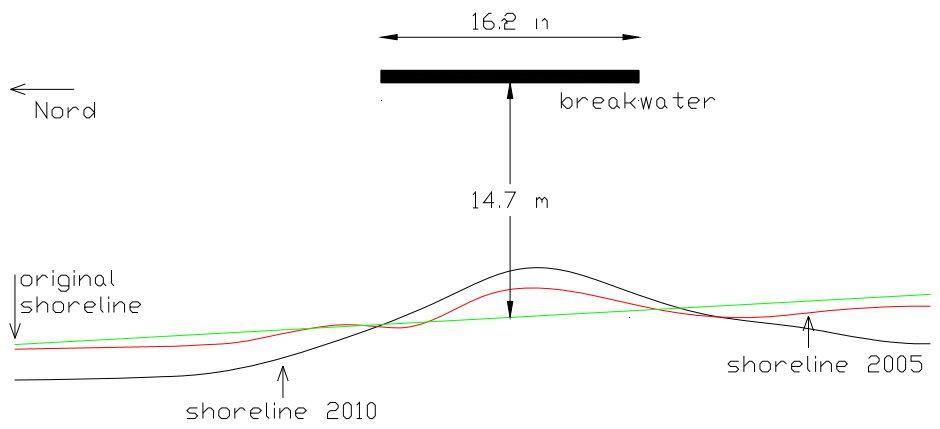

Figure 7: Measured shoreline: the green line is the shoreline before the breakwater placing (March 2005); the red line is the measured shoreline in June 2005 and the black line is the shoreline measured in September 2010.

Table 1: Modifications of the characteristic points of the shoreline. Data have been measured in June 2005 and in September 2010. Both data are compared to the shoreline measured in March 2005.

\begin{tabular}{|c|c|}
\hline Position & Modifications from 2005 to 2010 [\%] \\
\hline Salient & 11 \\
\hline Max erosion North & 13 \\
\hline Max erosion South & 11 \\
\hline Year & $\begin{array}{c}\text { Asymmetry max erosion North-Sud in the } \\
\text { shoreline [\%] }\end{array}$ \\
\hline 2005 & 12 \\
\hline 2010 & 14 \\
\hline
\end{tabular}

\subsection{Comparison between the theoretical models and the experimental data of RC 2010}

The afore-mentioned models have been used for estimating the distance between the salient apex and the breakwater, and the maximum distance between the axis parallel to the breakwater and the shoreline. Eq. (3), eq. (14) and Figure 4 have been used. Table 2 shows the results of the calculation. 
Table 2: $\quad$ Salient-breakwater distance and maximum distance between an axis parallel to the breakwater and the shoreline in the North side (N) and in the South side (S). It has been estimated the difference with respect to the 2010 shoreline (a positive quantity means overestimation and negative quantity means underestimation).

\begin{tabular}{|c|c|c|c|c|}
\hline Model & $\begin{array}{c}\text { Salient }- \\
\text { breakwater } \\
\text { distance } \\
{[\mathbf{m}]}\end{array}$ & $\begin{array}{c}\text { Difference } \\
\text { between } \\
\text { theoretical } \\
\text { results and } \\
\text { experimental } \\
\text { data [\%] }\end{array}$ & $\begin{array}{c}\text { Maximum } \\
\text { distance [m] }\end{array}$ & $\begin{array}{c}\text { Difference } \\
\text { between } \\
\text { theoretical } \\
\text { results and } \\
\text { experimental } \\
\text { data [\%] }\end{array}$ \\
\hline $\begin{array}{c}\text { Hsu and } \\
\text { Silvester }\end{array}$ & 9.77 & +16 & 18.96 & $\begin{array}{c}+1(\mathrm{~N}) \\
+15(\mathrm{~S})\end{array}$ \\
\hline McCormick & 12.09 & -4 & 14.71 & $-21(\mathrm{~N})$ \\
$-11(\mathrm{~S})$
\end{tabular}

Table 2 shows that Hsu and Silvester [1] model overestimates both the salient apex and the maximum erosion point in the South side, while it gives a good estimate of the maximum erosion point in the North side.

McCormick model [2] slightly underestimates the salient apex, but it overestimates the maximum erosion points.

Hsu et al. [3] model overestimates the salient and underestimates the maximum erosion points.

Gonzales and Medina [4] model gives a good estimated of the salient apex and the maximum erosion points. There are a small overestimation and a small underestimation, respectively, in the North side and in the South side of the shoreline.

\section{Conclusions}

Hsu and Silvester [1], McCormick [2], Hsu et al. [3] and Gonzalez and Medina [4] models for the determination of the shoreline change behind a breakwater have been analysed. The theoretical profiles have been compared to the experimental data. Data have been measured at the natural laboratory NOEL (Natural Ocean Engineering Laboratory) of Reggio Calabria. A breakwater for wave energy absorption has been place in 2005. It has been measures the shoreline in June 2005 (three months after the breakwater placing) and in 
September 2010. It has been shown that the shoreline is not symmetric with respect to the centre of the breakwater. Indeed, the salient apex is in the South side of the breakwater. This induces erosion in the North side of the shoreline. This asymmetry is due to the non-parallel position of the breakwater (it is intended non-parallel with respect to the shoreline) and to the occurrence of oblique wave trains.

The results have been summarized in Table 2. It has been shows that the best estimation is given by the Gonzales and Medina model. It gives a good estimate of shoreline measured in 2010. The other models are less accurate, but they are still capable of giving a first estimate of the shoreline change.

\section{References}

[1] Hsu, J.R.C., Silvester, R., Accretion behind single offshore breakwater. Journal of Waterway, Port, Coastal and Ocean Engineering, 116 (3). pp. 367-380, 1990.

[2] McCormick, M.E., Equilibrium shoreline response to breakwaters. Journal of Waterway, Port, Coastal and Ocean Engineering, 119 (6), pp. 657-670, 1993.

[3] Hsu, T.W., Jan, C.D., Wen, C.C., Modified Mc Cormick's model for equilibrium shorelines behind a detached breakwaters. Ocean Engineering, 30, pp. 1887-1897, 2003.

[4] Gonzalez, M., Medina, R., Equilibrium shoreline response behind a single offshore breakwater. Proceedings Coastal Sediment, 1, pp. 933-942, 1999.

[5] Shinohara, K., Tsubaki, T., Model study on the change of shoreline of sandy beach by the offshore breakwater. Proceedings $10^{\text {th }}$ International Conference of Coastal Engineering, Tokio, Japan, 1, pp. 550-563, 1966.

[6] Rosen, D.S., Vajda, M., Sedimentological influences of detached breakwaters. Proceedings $18^{\text {th }}$ International Conference of Coastal Engineering, 3, pp. 1930-1949, 1982.

[7] Mimura, H., Shimizu, T., Horikawa, K., Laboratory study of the influence of detached breakwaters on coastal changes. Proceedings Coastal Structures, 2, pp. 740-752, 1983.

[8] Ming D., Chiew Y.M., Shoreline changes behind detached breakwater. Journal of Waterway, Port, Coastal and Ocean Engineering, 126 (2), pp. 63-70, 2000.

[9] Gourlay, M.R., Beach processes in the vicinity of offshore breakwaters. Proceedings of $5^{\text {th }}$ Australian Conference on Coastal and Ocean Engineering, Perth, Australia, pp. 129-134, 1981.

[10] Shore Protection Manual, $4^{\text {th }}$ Ed., U.S. Army Corps of Engineer, Coastal Engineering Research Center, U.S. Government Printing Office, Washington, D.C., 1984.

[11] Dally, W.R., Pope, J., Detached breakwaters for shore protection. Technical Report CERC-86-1, U.S. Army Corps of Engineer, Coastal 
Engineering Research Center, Waterways Experiment Station: Vicksburg, Mississippi, USA, 1986.

[12] Suh, K., Dalrymple, R.A., Offshore breakwaters in laboratory and field. Journal of Waterway, Port, Coastal and Ocean Engineering, 113 (2), pp. 105-121, 1987.

[13] Ahrens, J.P., Cox, J., Design and performance of reef breakwaters. Journal of Coastal Research, 7, pp. 61-75, 1990.

[14] Gonzalez, M., Medina, R., On the application of static equilibrium bay formulations to natural and man-made beaches. Coastal Engineering, 43, pp. 209-225, 2000.

[15] Hsu, J.R.C., Evans, C., Parabolic bay shapes and applications. Proceedings of Institution of Civil Engineers, London, England, 87 (2), pp. 556-570, 1989.

[16] Boccotti P., Filianoti P., Fiamma V., Arena F., Caisson breakwaters embodying an OWC with a small opening. Part II: a small scale filed experiment. Ocean Engineering, 34, pp. 820-841, 2007.

[17] Boccotti P., Wave mechanics for Ocean Engineering, Elsevier: Amsterdam, 2000. 